\title{
ム Adis
}

\section{This material is the copyright of the original publisher. Unauthorised copying and distribution is prohibited.}

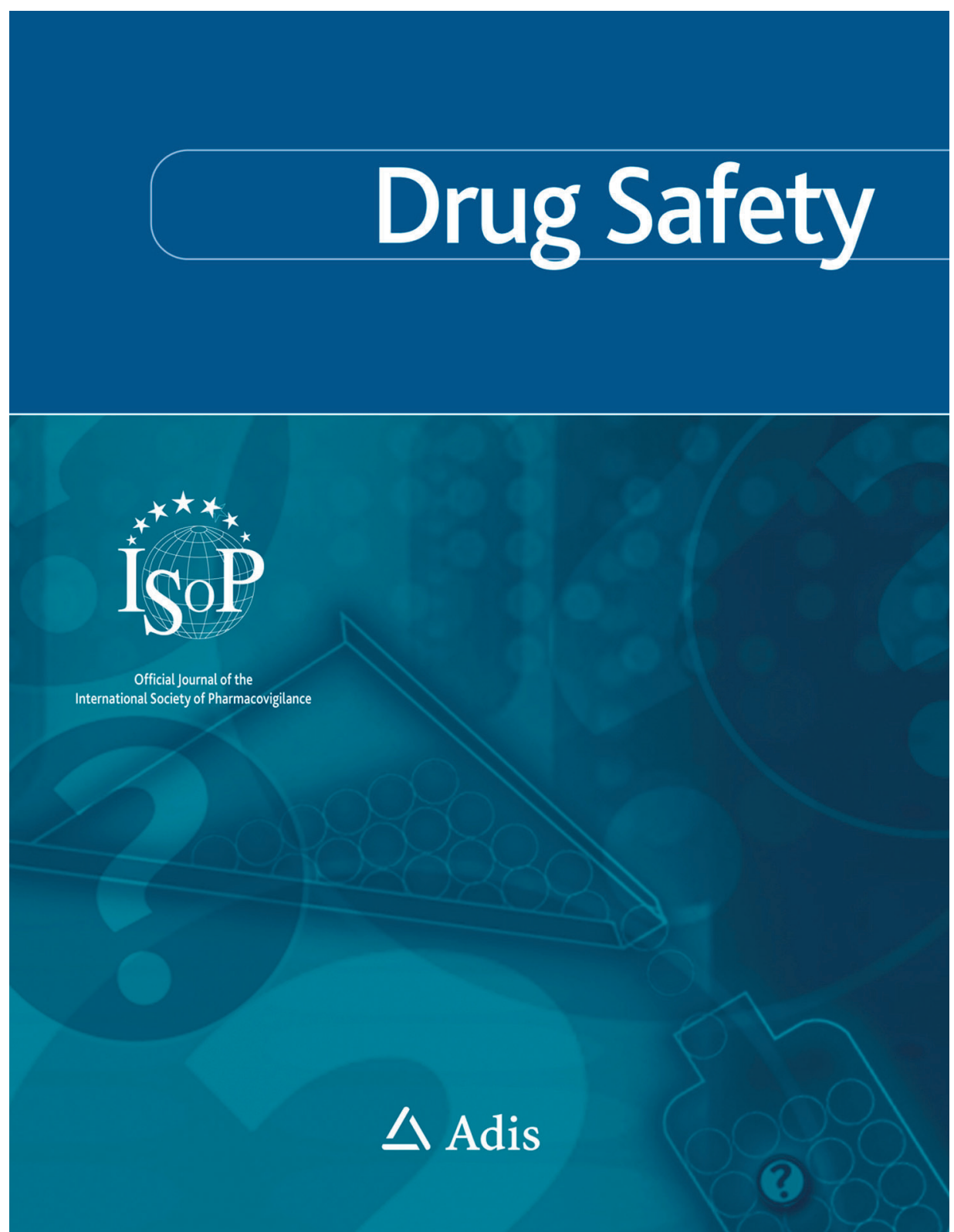

Terms and Conditions for Use of PDF

The provision of PDFs for authors' personal use is subject to the following Terms \& Conditions:

The PDF provided is protected by copyright. All rights not specifically granted in these Terms \& Conditions are expressly reserved. Printing and storage is for scholarly research and educational and personal use. Any copyright or other notices or disclaimers must not be removed, obscured or modified. The PDF may not be posted on an open-access website (including personal and university sites).

The PDF may be used as follows:

- to make copies of the article for your own personal use, including for your own classroom teaching use (this includes posting on a closed website for exclusive use by course students);

- to make copies and distribute copies (including through e-mail) of the article to research colleagues, for the personal use by such colleagues (but not commercially or systematically, e.g. via an e-mail list or list serve);

- to present the article at a meeting or conference and to distribute copies of such paper or article to the delegates attending the meeting;

- to include the article in full or in part in a thesis or dissertation (provided that this is not to be published commercially). 


\title{
Safety and Tolerability of Antiepileptic Drug Treatment in Children with Epilepsy
}

\author{
Renzo Guerrini, ${ }^{1}$ Gaetano Zaccara, ${ }^{2}$ Giancarlo la Marca ${ }^{1}$ and Anna Rosati ${ }^{1}$
}

1 Paediatric Neurology Unit and Laboratories, Children's Hospital A. Meyer, University of Florence, Florence, Italy

2 Neurology Unit, San Giovanni di Dio Hospital, Florence, Italy

\section{Contents}

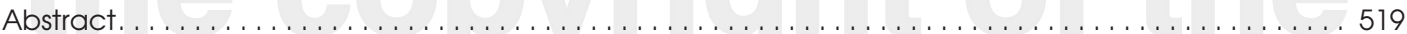

1. Criteria for Selection of Articles ........................................... 521



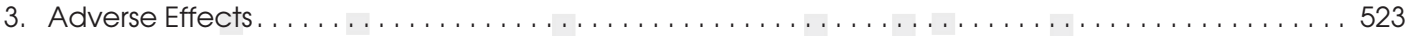

4. Dose-Related Adverse Effects ..................................... 523

4.1 Risk Factors for Dose-Related Adverse Effects . . . . . . . . . . . . . . . . . . . . . . . . . 523

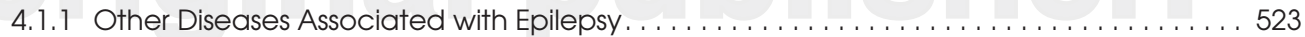

4.1 .2 Starting Dose and Titration Rate . . . . . . . . . . . . . . . . . . . . . . . . . . . . . 523

4.1 .3 Associated Drugs ............................................. 523

4.2 Most Frequent Dose-Related Adverse Effects to Antiepileptic Drugs (AEDs) . . . . . . . . . . . 523

5. Idiosyncratic Adverse Effects . . . . . . . . . . . . . . . . . . . . . . . . . . . . . . . . . 525

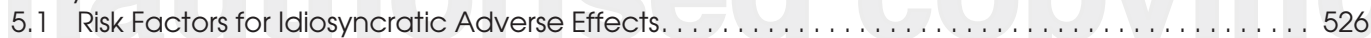

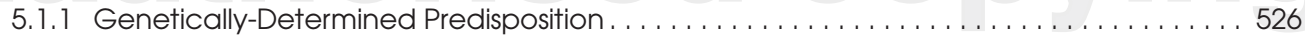



5.1 .3 Other Diseases Associated with Epilepsy . . . . . . . . . . . . . . . . . . . . . . . . . . . . 527

5.1 .4 Associated Drugs . . . . . . . . . . . . . . . . . . . . . . . . . . . . . . . . . . . . . 527



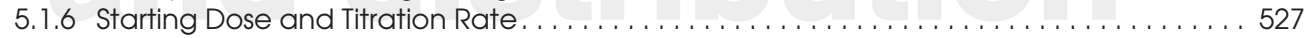



5.3 Cognitive Adverse Effects and Long-Term Safety. . . . . . . . . . . . . . . . . . . . . . . . . . . . . . 529

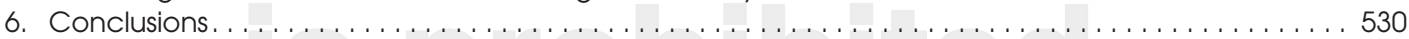

The aim of treating epilepsy is to control or at least decrease seizures without producing unacceptable adverse effects that impair quality of life. Antiepileptic drugs (AEDs) have been considered amongst the drugs most frequently associated with fatal suspected adverse drug reactions. Physicians must therefore be as familiar with safety and tolerability data of AEDs as they are with the expected therapeutic effects.

AEDs may cause dose-related adverse effects (i.e. drowsiness, fatigue, dizziness, blurry vision and incoordination) that, in most cases, may be obviated by lowering the dosage, reducing the number of drugs or switching to a better tolerated AED. AEDs also have the potential of precipitating idiosyncratic adverse effects (i.e. serious cutaneous, haematological and hepatic events), which are more common in children and usually require 
withdrawal of the AED. Although occurrence of idiosyncratic adverse effects can only rarely be predicted or prevented, there are known risk factors that can help in identifying patients at high risk. Occurrence of an idiosyncratic event in a close relative, a concomitant autoimmune disease, co-treatment with specific drugs, history of a previous allergic drug reaction, starting treatment with high doses and rapid titration have all been associated with a higher risk of idiosyncratic adverse effects.

New AEDs have been developed in the last two decades with the aim of improving the benefit-risk balance of AED therapy. Available evidence suggests that the newer AEDs are no more effective but may be somewhat better tolerated than older molecules.

We performed a literature review with the aim of evaluating safety and tolerability of second- and third-generation AEDs in children. A PubMed search was conducted with the purpose of identifying English-language studies published between 1 January 1989 and 1 January 2011 that reported any adverse event having occurred in children with epilepsy in whom secondand third-generation AEDs were administered.

Antiepileptic drugs (AEDs) have been considered amongst the drugs most frequently associated with fatal suspected adverse drug reactions in a UK study. ${ }^{[1]}$ As every AED has potential adverse effects, indications for introducing a new molecule in the treatment regimen should be carefully weighed with the objective of improving seizure control without producing drug-related undesirable effects that outweigh the desired therapeutic effects.

During the period 1989-2009, 14 new molecules with antiepileptic action have been developed. These second-generation AEDs comprise felbamate (FBM), gabapentin (GBP), lamotrigine (LTG), levetiracetam (LEV), oxcarbazepine (OXC), pregabalin (PGB), rufinamide (RUF), stiripentol (STP), tiagabine (TGB), topiramate (TPM), vigabatrin (GVG) and zonisamide (ZNS). Most recently, third-generation AEDs have been introduced, comprising eslicarbazepine acetate (ESL) and lacosamide (LCS).

Although newer AEDs have not demonstrated a superior efficacy compared with older molecules, most of them have been advertised as having a better tolerability profile, fewer drug interactions and simpler pharmacokinetics. ${ }^{[2,3]}$ However, our knowledge concerning their safety profiles is insufficient due to the limited number of patients exposed to them so far. ${ }^{[2,3]}$ Particularly in children, information on AED safety and tolerability is generally poor and is only acquired late, since approval for paediatric use is only granted with considerable delay, after promising results have been obtained in adults. Differences between children and adults in regard to drug safety and tolerability monitoring may be related to underreporting during off-label use $\mathrm{e}^{[4]}$ or underrecognition/ appreciation of adverse effects by caregivers. ${ }^{[5]}$

Some adverse effects, especially those related to CNS toxicity, are particularly insidious in young children and in those with neurological comorbidities and psychiatric or behavioural problems. ${ }^{[6]}$ A standardized adverse event questionnaire may be useful for monitoring adverse effects and optimizing AED therapy, ${ }^{[7]}$ although data on subjective symptoms are hardly obtained from young children.

We performed a literature review with the aim of evaluating safety and tolerability of secondand third-generation AEDs in children. A PubMed search was conducted with the purpose of identifying English-language studies published between 1 January 1989 and 1 January 2011 that reported any adverse event having occurred in children with epilepsy in whom second- and third-generation AEDs were administered. 


\section{Criteria for Selection of Articles}

For the review of safety and tolerability of the newer AEDs, we assessed available literature according to predefined criteria. We used the electronic database PubMed to identify articles published between 1 January 1989 and 1 January 2011 with the following limits: (i) age range between 0 and 18 years; and (ii) English language. The literature search identified all articles that included the terms 'epilepsy AND adverse effects AND eslicarbazepine OR felbamate OR gabapentin OR vigabatrin OR lacosamide OR levetiracetam OR lamotrigine $\mathrm{OR}$ oxcarbazepine $\mathrm{OR}$ pregabalin OR rufinamide OR stiripentol OR tiagabine OR topiramate OR zonisamide'. Studies including both children and adults were reviewed only if data on safety were reported separately for children. Since this review includes various adverse effects and several reports of single cases and small series, we chose to perform a descriptive analysis without pooling of data.

Data were reviewed for safety and tolerability information from 308 articles: 1 on ESL, 11 on FBM, 15 on GBP, 57 on GVG, 2 on LCS, 56 on LTG, 34 on LEV, 23 on OCX, 2 on PGB, 7 on RUF, 3 on STP, 16 on TGB, 55 on TPM and 26 on ZNS. The selection process of articles is reported in figure 1.

\section{Safety and Tolerability: General Considerations}

Optimal treatment of epilepsy first demands correct recognition of the types of seizures and correct diagnosis of the specific type of epilepsy or syndrome (table I). Seizure aggravation as a consequence of prescribing an inappropriate AED for the particular seizure type or because of a paradoxical exacerbation of seizures should be followed by prompt review of treatment ${ }^{[8-18]}$ (table II).

Once identified, the most appropriate AED, starting with low doses, slow titration, adequate posology choice and individualization of the minimal effective maintenance doses, may greatly improve safety and tolerability. ${ }^{[19]}$

Most of the new AEDs are being used with the belief that monitoring of serum levels is un-



Fig. 1. Selection process of articles.

necessary. Although monitoring of drug concentrations in the blood is not routinely indicated, some of the new AEDs exhibit such a wide interand intra-individual variability in absorption and kinetics that therapeutic monitoring is advised. ${ }^{[20]}$ The strongest cases for routine therapeutic drug monitoring can be made for LTG, OXC, STP, TGB and ZNS, mainly due to inter-individual variation in metabolism and clearance. ${ }^{[20]}$ Therapeutic drug monitoring has lower utility for GBP, PGB, GVG. ${ }^{[20]}$ There are no generally accepted target ranges for most of the newer AEDs and a wide range in serum concentration has been associated with clinical efficacy. ${ }^{[21]}$ Therefore, although routine monitoring cannot be recommended, it might still be useful to establish an individual reference level that helps avoid overtreatment and dosage adjustments in the presence of factors that might alter their pharmacokinetics. ${ }^{[22]}$ Monitoring is also needed to assess compliance when breakthrough seizures occur, to substantiate clinically suspected toxicity, and drug interactions.

When prescribing a polytherapy, the clinician must be fully aware of the potential for pharmacokinetic and pharmacodynamic AED interactions that influence the risk of developing adverse 
Table I. Main drugs for various types of epilepsy/syndrome in children

\begin{tabular}{lll}
\hline Epilepsy/syndrome & First-line & Second-line (monotherapy or add-on) $^{\text {a }}$ \\
\hline Symptomatic focal epilepsy & CBZ, VPA & LTG, OXC, TPM, GBP, LEV, PHT, PB, ZNS \\
IGE with absences & VPA, ESM & LTG, BDZs, LEV \\
IGE with myoclonus & VPA & ESM, BDZs, LEV, PB, TPM \\
IGE with GTCS & VPA & LTG, TPM, LEV, PB, BDZs \\
Infantile spasms & GVG, corticosteroids & BDZs, VPA, LTG \\
Dravet's syndrome & STP +VPA+CLB & BDZs, TPM, PB \\
Lennox-Gastaut syndrome and related syndromes & VPA \pm LTG & LTG, TPM, RUF, BDZs, CBZ, GBP, GVG, FBM
\end{tabular}

a Second-line or add-on because of no controlled studies in children, relatively limited clinical experience and/or high frequency of adverse effects.

$\mathbf{B D Z}=$ = benzodiazepines; $\mathbf{C B Z}=$ carbamazepine; $\mathbf{C L B}=$ clobazam; $\mathbf{E S M}=$ ethosuximide; $\mathbf{F B M}=$ felbamate; $\mathbf{G B P}=$ gabapentin; $\mathbf{G T C S}=$ generalized tonic-clonic seizures; GVG = vigabatrin; IGE = idiopathic generalized epilepsy; LEV = levetiracetam; LTG =lamotrigine; OXC= oxcarbazepine; $\mathbf{P B}=$ phenobarbital; $\mathbf{P H T}=$ phenytoin; $\mathbf{R U F}=$ rufinamide; $\mathbf{S T P}=$ stiripentol; TPM = topiramate; $\mathbf{V P A}=$ valproate; $\mathbf{Z N S}=$ zonisamide .

effects. ${ }^{[23]}$ The main pharmacokinetic interactions to consider in AED polytherapy are cytochrome P450 (CYP) metabolism competition and protein binding and displacement. Overall, newer AEDs have less potential for interactions due to minimal or null binding to blood albumin (e.g. ESL, FBM, GBP, LCS, LEV, RUF, TPM and GVG), and their primary renal excretion or metabolism by non-CYP enzymes or uridine glucoronyl transferases (e.g. GBP, LCS, LEV, RUF,TPM, GVG). ${ }^{[23,24]}$

Pharmacodynamic interactions can modify pharmacological effects and cause adverse ef- fects, without changes in drug concentrations. In particular, the adverse effects of any drug can be increased by other drugs with similar properties. One example is the reciprocal potentiation of the neurotoxic effects when sodium channel-blocking AEDs are coadministered. ${ }^{[25,26]}$

One unsolved issue concerns the usefulness of laboratory monitoring for the early identification of subclinical allergic or cytotoxic idiosyncratic reactions in asymptomatic patients. Although routine blood and urine screening should be obtained at baseline, only on rare occasions do these

Table II. Antiepileptic drugs that may aggravate some epileptic syndromes

\begin{tabular}{llll}
\hline Drug & Syndrome & Type of seizure worsening/precipitation & References \\
\hline BDZs & Lennox-Gastaut syndrome & Tonic seizures & 8,9 \\
CBZ & Absence epilepsy & Absences, myoclonus & $8-10$ \\
& Juvenile myoclonic epilepsy & Myoclonic seizures & \\
& Progressive myoclonus epilepsy & Myoclonus & \\
& Rolandic epilepsy & CSWS, negative myoclonus & $8,9,11$ \\
GBP & Absence epilepsy & Absences & $8,9,12$ \\
& Epilepsies with myoclonus & Myoclonus & \\
GVG & Absence epilepsy & Absences & $8,9,13,14$ \\
& Epilepsies with myoclonus & Myoclonus & $15-17$ \\
LTG & Focal cortical dysplasia & Myoclonic seizures & \\
& Severe myoclonic epilepsy & At high dosage & \\
OXC & Juvenile myoclonic epilepsy & Myoclonic seizures & \\
& Rolandic epilepsy & Atypical absences & \\
PB & Idiopathic generalized epilepsy & Myoclonic seizures & \\
PHT & Symptomatic generalized epilepsy & Myoclonic seizures & 8,9 \\
& Absence epilepsy & Absences & 18 \\
\hline
\end{tabular}

BDZs = benzodiazepines; CBZ = carbamazepine; CSWS=continuous spikes and waves during slow sleep; GBP=gabapentin; GVG= vigabatrin; $\mathbf{L T G}=$ lamotrigine; $\mathbf{O X C}=$ oxcarbazepine; $\mathbf{P B}=$ phenobarbital; $\mathbf{P H T}=$ phenytoin; $\mathbf{T G B}=$ tiagabine . 
results alert clinicians to the potential occurrence of severe adverse events. ${ }^{[27]}$ Laboratory monitoring is necessary if the patient is presenting with abnormal signs which suggest serious adverse effects such as bruising, bleeding, rash, abdominal pain, vomiting, jaundice, sedation, lethargy, coma and deterioration in seizure control. ${ }^{[28]}$

Regular clinical supervision, paying special attention to sedative adverse effects, is essential. The search for sedative adverse effects is especially difficult in infants or mentally impaired children $^{[29]}$ because marked cognitive and physical slowing may be erroneously attributed to seizures or to the causative disorder rather than to therapy. Slowing or worsening in school performance should always raise the possibility of an inappropriate choice of AED or an excessive dose.

\section{Adverse Effects}

Drug-induced adverse effects may be divided into two classes: 'dose-related or pharmacology-related' (Type A) and 'idiosyncratic' (Type B), although, at times, they do not necessarily fit either category.

\section{Dose-Related Adverse Effects}

Most dose-related adverse effects are generic and predictable, explained by the known pharmacological properties of the individual agent and usually observed at the beginning of treatment or following dosage increase (table III). They are usually reversible upon dosage adjustment and rarely require discontinuation of therapy. In controlled trials of AEDs, where different doses are compared, most adverse effects are dose related. ${ }^{[35,75,76]}$ Although information drawn from these studies may help choosing the daily doses that make adverse effects less likely, avoiding dose-related adverse effects may be very difficult as tolerance and adaptation to them vary widely among patients.

\section{1 Risk Factors for Dose-Related Adverse Effects}

\subsubsection{Other Diseases Associated with Epilepsy}

AEDs that are primarily metabolized in the liver, such as FBM, LTG and TGB, may rise to toxic levels in patients with liver disease. In these patients those drugs should not be considered as a first choice. If no alternatives exist, their use requires close monitoring of dosage. ${ }^{[71]}$ To avoid dose-related adverse effects in patients with renal disease, AEDs with predominantly renal excretion, such as GBP and TPM, should be avoided or used at low dosage. ${ }^{[77]}$ Children with refractory epilepsy who are co-treated with the ketogenic diet and carbonic anhydrase inhibitor AEDs, such as TPM and ZNS, are at risk for urolithiasis. ${ }^{[77]}$

\subsubsection{Starting Dose and Titration Rate}

The frequency and severity of most doserelated adverse effects is crucially influenced by the starting dose and titration speed. ${ }^{[78,79]}$ For this reason, particularly in the paediatric setting, special care should be taken not to exceed the recommended initial dose and speed of titration. A slow titration may also minimize CNS adverse effects by allowing pharmacodynamic tolerance and early detection of subtle or prodromal signs, which can, in turn, indicate that adverse effects might worsen with further dose increase. ${ }^{[6]}$ Doserelated adverse effects of AEDs may occur in individual patients even when AED levels are within the reference range. ${ }^{[22]}$ This problem arises, in part, because a reference range is only a statistical estimate, applying to a population of patients, indicating a range in which a therapeutic response is likely to occur without toxicity. However, there are large inter-individual differences with regard to the blood level that will result in a therapeutic response or toxicity. ${ }^{[21]}$

\subsubsection{Associated Drugs}

Dose-related adverse effects often increase when multiple AEDs are combined. Co-administration of two or more AEDs, or concomitant use of one or more drugs of a different class, also increase the potential toxicity of a given AED. ${ }^{[23,24]}$

\subsection{Most Frequent Dose-Related Adverse Effects to Antiepileptic Drugs (AEDs)}

The most commonly reported dose-related adverse effects in children are listed in table III, according to the involved anatomo-physiological systems (CNS, gastrointestinal system, skin and renal system). No rating order of frequency is 


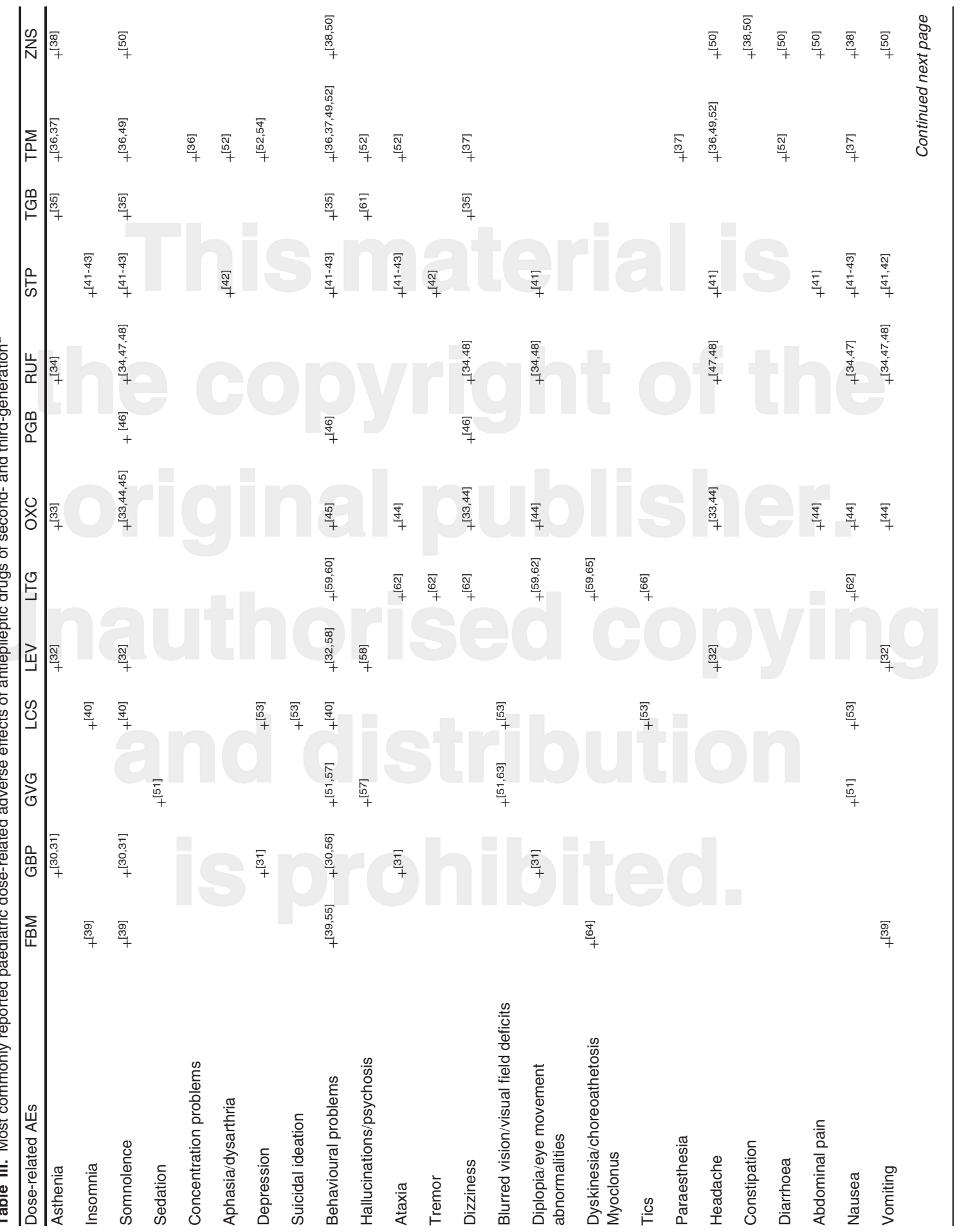




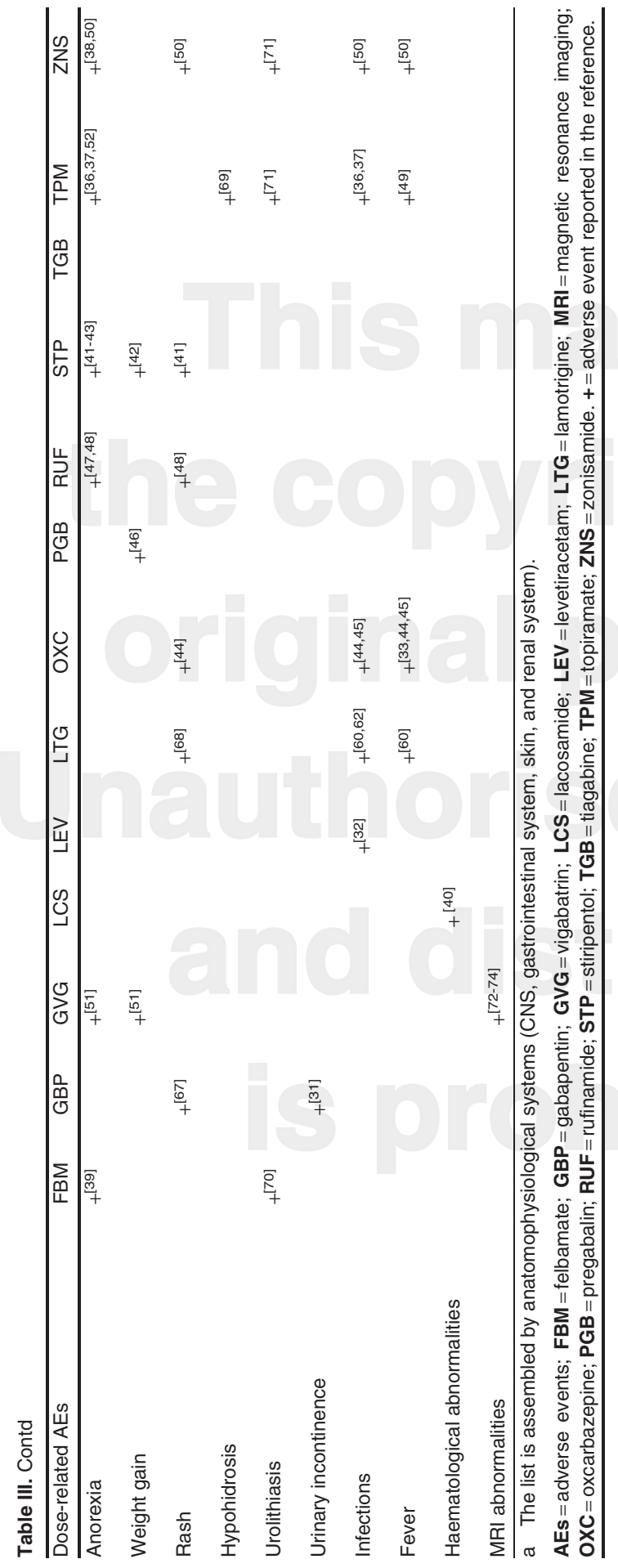

possible as the number of studies for each drug is widely variable. ${ }^{[30-68,70,72-74]}$

\section{Idiosyncratic Adverse Effects}

Idiosyncratic adverse effects (Type B) occur sporadically and unpredictably in susceptible individuals only, and irrespective of dosage. Their pathogenesis is apparently unrelated to the known mechanisms of action of the offending drug, but rather represents the consequence of an abnormal, often immunological, reaction. ${ }^{[80]}$ Considering the heterogeneity of the clinical presentations and the different properties of the causative agents, it is not surprising that idiosyncratic reactions involve a broad range of mechanisms and that more than one mechanism be involved for a single event. Schematically, the main pathogenetic mechanisms include:

Direct cytotoxicity: The idiosyncratic reaction is caused by a direct cytotoxic effect of the drug or its metabolites, without pathogenetic involvement of the immune system. ${ }^{[81]}$ The best example of such reactions is probably valproate (VPA)induced hepatotoxicity. There is experimental and clinical evidence for a direct cytotoxic effect of two VPA metabolites, namely 4-en VPA and its $\beta$-oxidation derivative 2,4-dien VPA. ${ }^{[82]}$ It has been shown that 2,4-diene-VPA is a reactive species capable of causing inhibition of $\beta$-oxidation and mitochondrial dysfunction. ${ }^{[83]}$ Since the formation of 4-en-VPA is largely catalyzed by CYP2C9, whose activity is inducible and higher in infants co-medicated with enzyme-inducing AEDs, this finding may explain why the risk of VPA-induced liver toxicity is highest in infants who are co-medicated with enzyme-inducing AEDs. ${ }^{[84]}$

Immune-mediated hypersensitivity reactions: These reactions involve abnormal humoral- or cell-mediated responses. AEDs may initiate these responses by interacting with cells of adaptive immunity. In this case, the drug, or a metabolite, needs to act as a hapten, i.e. it has to covalently bind and modify a macromolecule to become immunogenic. ${ }^{[85]}$ Alternatively, electrophilic metabolites can react with nucleophilic groups on proteins without covalent binding. ${ }^{[86]}$ The drug-peptide 
complex, which is recognized as foreign, is thus processed by antigen presenting cells that can, in turn, trigger B- or T-cell-mediated responses. The so called 'danger hypothesis' ${ }^{[87,88]}$ has been formulated to explain both the low incidence of hypersensitivity reactions in patients treated with such drugs, as well as the increased risk of developing them during viral infections, surgery and radiation therapy. In accordance with this hypothesis, inflammatory signals derived from cells that have been damaged, act on antigen presenting cells and $\mathrm{T}$ cells to trigger an immune-mediated reaction. ${ }^{[80]}$ Reactive drug metabolites are often the causative agents also in the case of immunemediated reactions as they may bind covalently to macromolecules and trigger an immune response. ${ }^{[89]}$ For instance, LTG, is mostly cleared by glucuronide conjugation and only minor amounts are converted by CYP enzymes to an arene oxide intermediate. Since VPA inhibits LTG glucuronidation, in patients co-medicated with VPA a higher percentage of the LTG dose is converted through the alternative CYP-mediated pathway to the oxide intermediate, which may explain the greater susceptibility of these patients to LTGinduced skin rashes ${ }^{\left[{ }^{[8]}\right.}$ Children are at higher risk of LTG-induced idiosyncratic reactions because their CYP enzymatic system is faster and glucuronide conjugation slower compared with adults. ${ }^{[83-90]}$ Considerable evidence indicates that FBM-induced liver and bone marrow toxicity is mediated by the reactive metabolite atropaldehyde. ${ }^{[91,92]}$ Both atropaldehyde and another FBM metabolite, alcohol carbamate, have been shown to inhibit glutathione transferase and cause cytotoxicity in human hepatocytes. ${ }^{[93]}$ Likewise, FBM metabolites form covalent adducts with human serum albumin. ${ }^{[94]}$ Since the half-life of the atropaldehyde precursors CPPA (3-carbamoyl-2-phenylpropionic acid) and 4-hydroxy-5phenyl-(1,3)-oxazinan-2-one is in the order of hours, it has been suggested that these FBM metabolites may travel from the liver and release atropaldehyde to other sites such as the bone marrow. ${ }^{[93,94]}$ Whether immune mechanisms play an important role in the toxicity of FBM metabolites is unclear, but their involvement is suggested by experimental studies on the immunogenic po- tential of reactive $\mathrm{FBM}$ metabolites ${ }^{[95]}$ and the observation that patients with a history of hypersensitivity reactions and autoimmune disease are at greater risk of developing FBM-induced aplastic anaemia. ${ }^{[96]}$

Off-target pharmacology: These reactions occur when a drug interacts directly with a system other than that for which it is intended. ${ }^{[97]} \mathrm{Ex}$ amples include some unusual CNS adverse effects such as Parkinsonian symptoms ${ }^{[98]}$ or cognitive deterioration ${ }^{[99]}$ with VPA, and dyskinesia with FBM. $^{[64]}$

\section{1 Risk Factors for Idiosyncratic Adverse Effects}

\subsubsection{Genetically-Determined Predisposition}

Identical twins may experience similar idiosyncratic reactions. ${ }^{[100]}$ Also siblings of patients who had immune-mediated idiosyncratic reactions to an aromatic AED such as phenytoin (PHT), carbamazepine (CBZ), phenobarbital (PB) and primidone (PRI) are at greater risk. ${ }^{[101]}$ The US FDA has recently made a labelling change to the drug information concerning CBZ in which it is recommended that before starting treatment with the drug all Asians be genotyped for the $H L A$ $B * 1502$ allele. ${ }^{[102]}$ Recent data implicate this allele as a marker for CBZ-induced Stevens-Johnson syndrome (SJS) and toxic epidermal necrolysis (TEN) in Han Chinese. ${ }^{[103]}$

\subsubsection{Age}

Children are more predisposed to idiosyncratic drug reactions than adults. For example, the incidence of SJS in children started on LTG has been estimated to be as high as $1: 100$ compared with $1: 1000$ in adults. ${ }^{[79]}$ Young age is also a major risk factor for VPA-induced toxic hepatitis, for which the highest risk is in infants younger than 2 years of age. ${ }^{[104]}$ The reasons for the increased risk of idiosyncratic drug reactions in infancy might be due to age-related differences in drug metabolism. ${ }^{[105]}$ In young infants, CYPmediated reactions are faster and glucuronide conjugation is reduced with respect to adults and this may lead to increased production of reactive metabolites. $^{[83]}$ 


\section{1.3 Other Diseases Associated with Epilepsy}

Concomitant diseases play an important role in the pathogenesis of several cytotoxic or allergic idiosyncratic adverse effects. Rheumatoid arthritis, systemic lupus erythematous, Hashimoto thyroiditis, panhypogammaglobulinemia, idiopathic thrombocytopenic purpura, high serum antinuclear antibody concentrations and a history of cytopenia or hypersensitivity to other AEDs are risk factors for FBM-induced aplastic anaemia. ${ }^{[80]}$ Hypersensitivity reactions to aromatic AEDs are more frequently observed in patients with other immune system disorders, systemic lupus erythematous, infectious diseases and in those who are under treatment with corticosteroids. VPA-induced liver toxicity is another example of an idiosyncratic adverse effect that is strongly influenced by concomitant conditions. Several metabolic disorders, including urea cycle defects, organic acidurias, multiple carboxylase deficiency, mitochondrial or respiratory chain dysfunction, cytochrome aa3 deficiency in muscle, pyruvate carboxylase deficiency and pyruvate dehydrogenase complex deficiency all predispose to VPA-induced hepatotoxicity. ${ }^{[80]}$ Patients with GM1 gangliosidosis type 2, spinocerebellar degeneration, Friedreich ataxia, Lafora body disease and Alpers-Huttenlocher disease are also more susceptible to VPA-induced hepatotoxicity. ${ }^{[106]}$

\subsubsection{Associated Drugs}

Associated drugs may strongly influence susceptibility to idiosyncratic adverse reactions. For example, enzyme-inducing AEDs increase the incidence of VPA-induced liver toxicity, pancreatitis, hyperammonemia and encephalopathy. ${ }^{[107]}$ Concomitant treatment with VPA increases the risk of LTG-induced hypersensitivity. ${ }^{[80]}$

\section{1.5 History of Previous Allergic Drug Reactions}

Risk of having a further rash when initiating a new drug is generally increased in a patient who has already had a previous drug-induced rash. Cross-sensitivity among aromatic AEDs occurs in about half of patients. ${ }^{[108]}$ In particular, caution should be taken when prescribing LTG and $\mathrm{OXC}$ in patients with a history of rash to another AED or non-AED medication. ${ }^{[108]}$

\section{1.6 Starting Dose and Titration Rate}

The risk of allergic reactions is greatly increased when treatment is started at high doses, rapidly increased, or both, possibly because slow titration may allow desensitization to occur. ${ }^{[19]}$ A relationship between starting dose, titration rate and the incidence of cutaneous reactions is particularly obvious for LTG. ${ }^{[79]}$

\subsection{Most Frequent Idiosyncratic Adverse Effects to AEDs}

Due to their clinical relevance, idiosyncratic adverse effects of older AEDs are also considered (table IV).

Cutaneous manifestations are the most common idiosyncratic reactions caused by AEDs. The severity ranges from very benign mild skin rashes, which are usually morbilliform or maculopapular and occur shortly after starting therapy, to potentially life-threatening dermatological diseases such as rash with eosinophilia and systemic symptoms (DRESS), SJS and TEN (Lyell's syndrome).

DRESS, which is also named anticonvulsant hypersensitivity syndrome, is characterized by fever, skin eruption, eosinophilia, atypical lymphocytosis, arthralgia, lymphadenopathy and multi-organ involvement ${ }^{[109]}$ and is observed most frequently with the aromatic AEDs PHT and CBZ, with incidences of about $1-5$ cases per 10000 exposures.

In an analysis from the International Case Control Study on Severe Cutaneous Adverse Reactions (1989-1995), 21\% of the SJS and TEN cases reported intake of an AED. ${ }^{[110]}$ The risk of developing SJS and TEN was greatest in the first 8 weeks following onset of treatment. The risk of SJS and TEN was highest with CBZ, PB and PTH therapy. SJS and TEN may present as a febrile illness unexplained by an infections illness. Patients might experience symptoms resembling an upper respiratory tract infection, which precede the mucocutaneous lesions of SJS and TEN by 1-3 days. A skin detachment of less than $10 \%$ defines SJS, while a detachment that is more than $30 \%$ defines TEN. Ocular sequelae, including longterm conjunctivitis and blindness, may follow the acute phase in up to $35 \%$ of TEN patients and a smaller percentage of those with SJS. ${ }^{[111,112]}$ 
Table IV. Suggested daily dosage, severe adverse effects of antiepileptic drugs in children

\begin{tabular}{|c|c|c|}
\hline & Usual dose (oral; mg/kg/day) & Severe adverse effects \\
\hline \multicolumn{3}{|c|}{ First-generation antiepileptic drugs } \\
\hline Carbamazepine & $10-20$ & Aplastic anaemia, agranulocytosis, SJS/TEN, liver toxicity, pancreatitis, SLE \\
\hline Clobazam & $0.5-1$ (maximum 30 mg/day) & No \\
\hline Clonazepam & $0.1-0.2$ & Respiratory depression (only IV route) \\
\hline Ethosuximide & $20-30$ & Aplastic anaemia, agranulocytosis, SJS/TEN, liver toxicity, SLE \\
\hline Phenobarbital & $\begin{array}{l}15-20 \text { IV in newborns; } \\
3-5<5 \text { years } \\
2-3>5 \text { years }\end{array}$ & Agranulocytosis, SJS/TEN, liver toxicity, SLE \\
\hline Nitrazepam & $0.25-2.50$ & Drooling and aspiration causing pneumonia \\
\hline Phenytoin & $\begin{array}{l}15-20 \text { IV in newborns; } \\
8-10<3 \text { years; } \\
4-7>3 \text { years }\end{array}$ & $\begin{array}{l}\text { Megaloblastic anaemia, lymphoma, agranulocytosis, SJS/TEN, liver toxicity, SLE, } \\
\text { encephalopathy, choreoathetosis }\end{array}$ \\
\hline Primidone & $10-20$ & Agranulocitosis, SJS/TEN, liver toxicity, SLE \\
\hline $\begin{array}{l}\text { Sodium } \\
\text { valproate }\end{array}$ & $15-40$ & SJS/TEN, liver toxicity, SLE, pancreatitis, encephalopathy \\
\hline \multicolumn{3}{|c|}{ Second and third-generation antiepileptic drugs } \\
\hline Felbamate & $15-45$ & Aplastic anaemia, agranulocytosis, SJS/TEN, liver toxicity, pancreatitis, SLE \\
\hline Gabapentin & $25-35$ & SJS/TEN, liver toxicity, behavioural problem/hostility \\
\hline Lacosamide & 200-400 (in adults) & 01010 \\
\hline Lamotrigine & $\begin{array}{l}\text { 5-15 (add-on enzyme inducers); } \\
\text { 1-3 (add-on VPA); } \\
\text { 1-5 (add-on VPA+inducer) }\end{array}$ & Aplastic anaemia, SJS/TEN, liver toxicity, pancreatitis, Lyell's syndrome \\
\hline Levetiracetam & $20-40$ & Psychotic events, liver toxicity, pancreatitis \\
\hline Oxcarbazepine & $30-45$ & SJS/TEN, liver toxicity \\
\hline Rufinamide & $30-40$ & No \\
\hline Stiripentol & 50 & No \\
\hline Tiagabine & $0.5-2$ & SJS/TEN, non-convulsive status epilepticus \\
\hline Topiramate & $4-6$ & SJS/TEN, liver toxicity, pancreatitis \\
\hline Vigabatrin & $\begin{array}{l}20-80 \text {; } \\
100-150 \text { for infantile spasms }\end{array}$ & Liver toxicity, pancreatitis, psychosis, visual field defects, encephalopathy \\
\hline Zonisamide & $4-12$ & Aplastic anaemia, agranulocytosis, SJS/TEN, liver toxicity, psychiatric disorders \\
\hline
\end{tabular}

About $5 \%$ of patients with SJS and $30 \%$ of patients with TEN die from their disease. ${ }^{[111,113]}$ Bacterial infection and respiratory illness are often responsible for mortality resulting from SJS or TEN. ${ }^{[114,115]}$

Aplastic anaemia is the most frequent and serious haematological reaction reported with AEDs. FBM is by far the AED with the highest potential for causing this complication with a risk rate of 1 in 5000-10000. ${ }^{[16]}$ The incidence of CBZ-induced aplastic anaemia is between $1: 50000$ and $1: 200000$ exposed patients. ${ }^{[117]}$ More rarely, selective suppression of bone marrow cells may also lead to agranulocytosis and pure cell aplasia.
Sporadic cases of thrombocytopenia, probably immune-mediated, have been described. ${ }^{[117]}$

Hepatotoxicity is frequently observed in patients with idiosyncratic adverse reactions because liver is the primary organ responsible for drug metabolism and, therefore, more exposed to reactive metabolites. Hepatitis may be one of the symptoms of DRESS or occur in isolation, especially if caused by immune-mediated mechanisms or direct cytotoxic damage. ${ }^{[118]}$ Pancreatitis is a rare complication of VPA therapy with a mortality rate that has been estimated at $21 \% .{ }^{[119]}$ Several idiosyncratic adverse effects caused by the phenomenon of off-target pharmacology involve 
CNS. Some examples are VPA-induced encephalopathy ${ }^{[99,120]}$ and PHT-induced dyskinesia. ${ }^{[121]}$ Other systems or organs can also be involved. Acute secondary angle-closure glaucoma, acute bilateral myopia and suprachoroidal effusion are ocular reactions induced by TPM. ${ }^{[122]}$ Another example is VPA-induced Fanconi's syndrome. ${ }^{[123]}$

\subsection{Cognitive Adverse Effects and Long-Term Safety}

While adverse effects that are circumscribed and have clear onset are relatively easy to identify, toxicities that emerge insidiously (e.g. progressive cognitive slowing) may escape detection or their drug-induced determinism may remain obscure. There is no standardized definition of what constitutes 'long-term' safety or tolerability; this terminology is used in the literature referring to periods of at least 6 months to many years. Furthermore, there are no standardized instruments used in clinical practice for assessing drugassociated adverse effects.

Cognitive impairment, which often occurs in children with epilepsy, is in part attributed to AEDs. ${ }^{[6]}$ Since AEDs exert their antiepileptic properties mainly by modulating ion channels, neurotransmitters and second messengers, they can sometimes interfere with brain pathways involved in learning, memory and emotional behaviour. Special attention should be given to CNS adverse effects that involve cognition, thought processes, memory, speech, coordination and gait, as well as the appearance of lethargy, emotional and behavioural reactions, psychotic or depressive symptoms or suicidal behaviour/ideation. Although a detrimental dose-dependent effect of some AEDs on cognition is self-evident, only a few controlled studies have addressed this point in children. ${ }^{[124]}$ Clear evidence has been obtained about the reduction of intelligence quotient scores and increased P300 wave latency, an electrophysiological marker of reduced speed in cognitive processing, in children treated with PB. ${ }^{[125]}$

The long-term cognitive effects of newer AEDs in children are largely unknown. ${ }^{[6]}$ Few well designed studies have systematically investigated the cognitive effects of newer AEDs in children and adolescents in the short term. Open-label studies indicate that $\mathrm{OXC}$ monotherapy had no impact on cognitive function and intelligence over 6 months in children and adolescents with newly diagnosed partial-onset seizures, ${ }^{[126]}$ whereas the cognitive effects of TPM over 28 weeks were slightly worse than those of CBZ in children with benign rolandic epilepsy. ${ }^{[127]} \mathrm{A}$ retrospective analysis of long-term use of LEV and TPM showed that cognitive adverse effects in children and adults with epilepsy were more common with TPM than with LEV and more frequently led to drug withdrawal. ${ }^{[28]}$ Amongst children and adults treated with LEV, a minority can develop acute psychosis consisting of visual or auditory hallucinations and delirium within the first few weeks of treatment. ${ }^{[129]}$ A previous history of mental illness greatly increases the risk for psychotic symptoms. This adverse effect responds promptly to drug withdrawal or reduction. ${ }^{[129]}$

The report of irreversible concentric visual field defect in $30-50 \%$ of patients of all ages treated with $\mathrm{GVG}^{[51,63]}$ implies that there is a need for careful evaluation of the risk versus benefit issues before it is prescribed. This is a point of major concern since GVG is effective, and well tolerated, in the treatment of infantile spasms but the visual defect is asymptomatic and indefinable in the infantile spasms age group. It is still unclear if GVG-related visual field defects may represent an idiosyncratic adverse effect ${ }^{[130]}$ rather than result from dose-dependent toxicity. ${ }^{[63]}$ Its exact pathophysiological mechanisms remain unclear, but the site of toxicity could be the inner layer of retina, where GVG causes irreversible inhibition of GABA aminotransferase. ${ }^{[131]}$ A mild defect could be of very little clinical significance, especially in children with severe developmental disabilities. The relationship between duration of exposure to the drug and development of visual field defect has not yet been exactly established. Although a correlation with total GVG load seems to exist, ${ }^{[63]}$ a dose-dependent mechanism has been questioned. ${ }^{[130]}$ As most responses to GVG treatment are obtained within the initial 3 weeks, non-responders will have little risk, if any, of developing a visual field defect if the drug is promptly withdrawn. In responders, it has been 
suggested that GVG be discontinued after about 6 months. ${ }^{[132]}$ Nousiainen et al. ${ }^{[133]}$ (2001) found that after GVG withdrawal no significant recovery was observed in visual field but, conversely, no progression was found with continued therapy. Whether to switch to an alternative treatment or to no treatment should be planned according to the individual clinical and EEG characteristics. Symmetric magnetic resonance imaging (MRI) hyperintensities (T2 and DWI sequences) and magnetic resonance spectroscopy (MRS) abnormalities have been described in the globus pallidi, thalami, dentate nuclei and cerebral peduncles of patients with infantile spasms treated with GVG. ${ }^{\left[{ }^{72-74]}\right.}$ MRI abnormalities, which are supposed to depend on both high GVG dosage and younger age, are transient and disappear after GVG withdrawal. ${ }^{[72,73]}$ MRS changes, in contrast, persist after GVG discontinuation; this might indicate that these changes are related to seizure activity rather than a direct drug effect. ${ }^{[74]}$ However, the potential pathogenic mechanisms remain unclear.

\section{Conclusions}

Preventing and managing adverse effects during AED therapy is a major challenge. Strategies for reducing common dose-related adverse effects include optimal AED selection, slow titration and reduction of co-therapy, leaving the patient on monotherapy whenever feasible. Idiosyncratic adverse effects cannot be reliably predicted based on currently available knowledge, but careful history taking and clinical observation can help with reducing their frequency and limiting their severity. In addition to the considerations that apply to all ages, it is important for clinicians to be aware of the differences between adults and children with regard to the nature and frequency of AED adverse effects, so that these can be avoided or at least minimized in younger patients.

\section{Acknowledgements}

No sources of funding were used to assist in the preparation of this review. The authors have no conflicts of interest that are directly relevant to the content of this review.

\section{References}

1. Clarkson A, Chaoonara I. Surveillance for fatal suspected adverse drug reactions in the UK. Arch Dis Child 2002; 87: $462-7$

2. Connock M, Frew E, Evans BW, et al. The clinical effectiveness and cost-effectiveness of newer drugs for children with epilepsy: a systematic review. Health Technol Assess 2006; 10: iii, ix-118

3. Chu-Store C, Thiele EA. New drugs for pediatric epilepsy. Semin Pediatr Neurol 2010; 17: 214-23

4. Johann-Liang R, Pharm JW, Chen M, et al. Pediatric drug surveillance and the food and drug administration's adverse event reporting system: an overview of reports, 2003-2007. Pharmacoepidemiol Drug Saf 2009; 18: 24-7

5. Shah SS, Hall M, Goodman DM, et al. Off-label drug use in hospitalized children. Arch Pediatr Adolesc Med 2007; 161: $282-90$

6. Kennedy GM, Lhatoo SD. CNS adverse events associated with antiepileptic drugs. CNS Drugs 2009; 22: 739-60

7. Gillham R, Baker G, Thompson R, et al. Standardisation of a self-report questionnaire for use in evaluating cognitive, affective and behavioural side-effects of anti-epileptic drug treatment. Epilepsy Res 1996; 24: 47-55

8. Guerrini R, Belmonte A, Genton P. Antiepileptic druginduced worsening of seizures in children. Epilepsia 1998; 39 Suppl. 3: S2-10

9. Gayatri NA, Livingston JH. Aggravation of epilepsy by anti-epileptic drugs. Dev Med Child Neurol 2006; 48: 394-8

10. Parmeggiani L, Seri S, Bonanni P, et al. Electrophysiological characterization of spontaneous and carbamazepineinduced epileptic negative myoclonus in benign childhood epilepsy with centro-temporal spikes. Clin Neurophysiol 2004; 115: 50-8

11. Asconape J, Diedrich A, Della Badia J. Myoclonus associated with the use of gabapentin. Epilepsia 2000; 41: 479-81

12. Lortie A, Chiron C, Mumford J, et al. The potential for increasing seizure frequency, relapse, and appearance of new seizure types with vigabatrin. Neurology 1993; 43 Suppl. 5: S24-7

13. Guerrini R, Belmonte A, Parmeggiani L, et al. Myoclonic status epilepticus following high dose lamotrigine therapy. Brain Dev 1999; 21: 420-4

14. Cerminara C, Montanaro ML, Curatolo P, et al. Lamotrigine-induced seizure aggravation and negative myoclonus in idiopathic rolandic epilepsy. Neurology 2004; 63: 373-5

15. Chapman K, Holland K, Erenberg G. Seizure exacerbation associated with oxcarbazepine in idiopathic focal epilepsy of childhood. Neurology 2003; 61: 1012-3

16. Gelisse P, Genton P, Kuate C, et al. Worsening of seizures by oxcarbazepine in juvenile idiopathic generalized epilepsies. Epilepsia 2004; 45: 1282-6

17. Kaddurah AK, Holmes GL. Possible precipitation of myoclonic seizures with oxcarbazepine. Epilepsy Behav 2006; 8: 289-93

18. Skardoutsou A, Voudris KA, Vagiakou EA. Nonconvulsive status epilepticus associated with tiagabine therapy in children. Seizure 2003; 12: 599-601

19. Ferrendelli JA. Concern with antiepileptic drug initiation: safety, tolerability, and efficacy. Epilepsia 2001; 42 Suppl 4: $28-30$ 
20. Johannessen SI, Tomson T. Pharmacokinetic variability of newer antiepileptic drugs: when is monitoring needed? Clin Pharmacokinet 2006; 45: 1061-75

21. Krasowski M. Therapeutic drug monitoring of the newer anti-epilepsy medications. Pharmaceuticals 2010; 3: 1909-35

22. Patsalos PN, Berry DJ, Bourgeois BF, et al. Antiepileptic drugs-best practice guidelines for therapeutic drug monitoring: a position paper by the subcommission on therapeutic drug monitoring. ILAE Commission on Therapeutic Strategies. Epilepsia 2008; 49: 1239-76

23. Patsalos PN, Perucca E. Clinically important drug interactions in epilepsy: general features and interactions between antiepileptic drugs. Lancet Neurol 2003; 2: 347-56

24. Johannessen Landmark C, Patsalos PN. Drug interactions involving the new second- and third-generation antiepileptic drugs. Expert Rev Neurother 2010; 10: 119-40

25. Besag FM, Berry DJ, Pool F, et al. Carbamazepine toxicity with lamotrigine: pharmacokinetic or pharmacodynamic interaction? Epilepsia 1998; 39: 183-7

26. Novy J, Patsalos PN, Sander JW, et al. Lacosamide neurotoxicity associated with concomitant use of sodium channel-blocking antiepileptic drugs: a pharmacodynamic interaction? Epilepsy Behav 2011; 20: 20-3

27. Pellock JM, Willmore LJ. A rational guide to routine blood monitoring in patients receiving antiepileptic drugs. Neurology 1991; 41: 961-4

28. Camfield P, Camfield C. Monitoring for adverse effects of antiepileptic drugs. Epilepsia 2006; 47 Suppl. 1: 31-4

29. Bourgeois BF. Determining the effects of antiepileptic drugs on cognitive function in pediatric patients with epilepsy. J Child Neurol 2004; Suppl 1: 15-24

30. Korn-Merker E, Borusiak P, Boenigk HE. Gabapentin in childhood epilepsy: a prospective evaluation of efficacy and safety. Epilepsy Res 2000; 39: 27-32

31. Appleton R, Fichtner K, LaMoreaux L, et al. Gabapentin as add-on therapy in children with refractory partial seizures: a 24-week, multicenter, open-label study. Dev Med Child Neurol 2001; 43: 269-73

32. Levisohn PM, Mintz M, Hunter SJ, et al. Neurocognitive effects of adjunctive levetiracetam in children with partialonset seizures: a randomized, double-blind, placebocontrolled, noninferiority trial. Epilepsia 2009; 50: 2377-89

33. Martinez W, Ingenito A, Blakeslee M, et al. Efficacy, safety, and tolerability of oxcarbazepine monotherapy. Epilepsy Behav 2006; 9: 448-56

34. Wier HA, Cerna A, So TY. Rufinamide for pediatric patients with Lennox-Gastaut syndrome: a comprehensive overview. Paediatr Drugs 2011; 13 (2): 97-106

35. Uldall P, Bulteau C, Pedersen SA, et al. Tiagabine adjunctive therapy in children with refractory epilepsy: a single-blind dose escalating study. Epilepsy Res 2000; 42: 159-68

36. Rosenfeld WE, Doose DR, Walker SA, et al. A study of topiramate pharmacokinetics and tolerability in children with epilepsy. Pediatr Neurol 1999; 20: 339-44

37. Arroyo S, Dodson WE, Privitera MD, et al. Randomized dose-controlled study of topiramate as first-line therapy in epilepsy. Acta Neurol Scand 2005; 112: 214-22

38. Kluger G, Zsoter A, Holthausen H. Long-term of zonisamide in refractory childhood-onset epilepsy. Eur J Paediatr Neurol 2008; 12: 19-23
39. Grosso S, Cordelli DM, Coppola G, et al. Efficacy and safety of felbamate in children under 4 years of age: a retrospective chart review. Eur J Neurol 2008; 15: 940-6

40. Gavatha M, Ioannou I, Papavasiliou SA. Efficacy and tolerability of oral lacosamide as adjunctive therapy in pediatric patients with pharmacoresistant focal epilepsy. Epilepsy Behav 2001; 20: 691-3

41. Perez J, Chiron C, Musial C, et al. Stiripentol: efficacy and tolerability in children with epilepsy. Epilepsia 1999; 40: 1618-26

42. Chiron C, Marchand MC, Tran A, et al. Stiripentol in severe myoclonic epilepsy in infancy: a randomised placebocontrolled syndrome-dedicated trial. STICLO study group. Lancet 2000; 356 (9242): 1638-42

43. Inoue $\mathrm{Y}$, Ohtsuka $\mathrm{Y}$, Oguni $\mathrm{H}$, et al. Stiripentol open study in Japanese patients with Dravet syndrome. Epilepsia 2009; 50: 2362-8

44. Bourgeois BF, D'Souza J. Long-term safety and tolerability of oxcarbazepine in children: a review of clinical experience. Epilepsy Behav 2005; 7: 375-82

45. Northam RS, Hernandes AW, Litzinger MJ, et al. Oxcarbazepine in infants and young children with partial seizures. Pediatr Neurol 2005; 33: 337-44

46. Jan MM, Zuberi SA, Alsaihati BA. Pregabalin: preliminary experience in intractable childhood epilepsy. Pediatr Neurol 2009; 40: 347-50

47. Wheless JW, Conry J, Krauss G, et al. Safety and tolerability of rufinamide in children with epilepsy: a pooled analysis of 7 clinical studies. J Child Neurol 2009; 24: 1520-5

48. Vendrame M, Loddenkemper T, Gooty VD, et al. Experience with rufinamide in a pediatric population: a single center's experience. Pediatr Neurol 2010; 43: 155-8

49. Cho YJ, Heo K, Kim WJ, et al. Long-term efficacy and tolerability of topiramate as add-on therapy in refractory partial epilepsy: an observational study. Epilepsia 2009; 50: 1910-9

50. Shinnar S, Pellock JM, Conry JA. Open-label, long-term safety study zonisamide administered to children and adolescents with epilepsy. Eur J Paediatr Neurol 2009; 13: 3-9

51. Dalla Bernardina B, Fontana E, Vigevano F, et al. Efficacy and tolerability of vigabatrin in children with refractory partial seizures: a single-blind dose-increasing study. Epilepsia 1995; 36: 687-91

52. Mohamed K, Appleton R, Rosenbloom L. Efficacy and tolerability of topiramate in childhood and adolescent epilepsy: a clinical experience. Seizure 2000; 9: 137-41

53. Guilhoto LM, Loddenkemper T, Gooty VD, et al. Experience with lacosamide in a series of children with drugresistant focal epilepsy. Pediatr Neurol 2001; 55: 414-9

54. Gross-Tsur V, Shalev RS. Reversible language regression as an adverse effect of topiramate treatment in children. Neurology 2004; 62: 299-300

55. Gay PE, Mechman GF, Coskey JS, et al. Behavioral effects of felbamate in childhood epileptic encephalopathy (Lennox-Gastaut syndrome). Psychol Rep 1995; 77 : 1208-10

56. Mikati MA, Choueri R, Khurana DS, et al. Gabapentin in the treatment of refractory partial epilepsy in children with intellectual disability. J Intellect Disabil Res 1998; 42 Suppl 1: 57-62 
57. Ferrie CD, Robinson RO, Panayiotopoulos CP. Psychotic and severe behavioural reactions with vigabatrin: a review. Acta Neurol Scand 1996; 93: 1-8

58. Verrotti A, D'Adamo E, Parisi P, et al. Levetiracetam in childhood epilepsy. Paediatr Drugs 2010; 12: 177-86

59. Das KB, Harris C, Smyth DP, et al. Unusual side effects of lamotrigine therapy. J Child Neurol 2003; 18: 479-80

60. Piña-Garza JE, Elterman RD, Ayala R, et al. Long-term tolerability and efficacy of lamotrigine in infants 1 to 24 months old. J Child Neurol 2008; 23: 853-61

61. Sackellares JC, Krauss G, Sommerville KW, et al. Occurrence of psychosis in patients in patients with epilepsy randomzed to tiagabine or placebo treatment. Epilepsia 2002; 43: 394-8

62. Messnheimer J. Efficacy and safety of lamotrigine in pediatric patients. J Child Neurol 2002; 17 Suppl 2: 34-42

63. Conway M, Cubbidge RP, Hosking SL. Visual field severity indices demonstrate dose-dependent visual loss from vigabatrin therapy. Epilepsia 2008; 49: 108-16

64. Kerrick JM, Kelly BJ, Maister BH, et al. Involuntary movement disorders associated with felbamate. Neurology 1995; 45: 185-7

65. Zesiewicz TA, Sullivan KL, Hauser RA. Chorea induced by lamotrigine [letter]. J Child Neurol 2006; 21: 357

66. Sotero De Menezes MA, Rho JM, Murphy P, et al. Lamotrigine-induced tic disorder: report of five pediatric cases. Epilepsia 2000; 41: 862-7

67. Gijsen VM, de Wildt SN, Ito S. Probability of rash related to gabapentin therapy in a child. Ann Pharmacother 2009; 43: $387-9$

68. Dooley J, Camfield P, Gordon K, et al. Lamotrigineinduced rash in children. Neurology 1996; 46: 240-2

69. Kim SC, Seol IJ, Kim SJ. Hypohidrosis-related symptoms in pediatric epileptic patients with topiramate. Pediatr Int 2010; 52: 109-12

70. Sparagana SP, Strand WR, Adams RC. Felbamate urolithiasis. Epilepsia 2001; 42: 682-5

71. Lacerda G, Krummel T, Sabourdy C, et al. Optimizing therapy of seizures in patients with renal or hepatic dysfunction. Neurology 2006; 67 Suppl. 4: 28-33

72. Pearl PL, Vezina LG, Saneto RP, et al. Cerebral MRI abnormalities associated with vigabatrin therapy. Epilepsia 2009; 50: 184-94

73. Wheless JW, Carmant L, Bebin M, et al. Magnetic resonance imaging abnormalities associated with vigabatrin in patients with epilepsy. Epilepsia 2009; 50: 195-205

74. Thelle T, Gammelgaard L, Hansen JK, et al. Reversible magnetic resonance imaging and spectroscopy abnormalities in the course of vigabatrin treatment for West syndrome. Eur J Paediatr Neurol 2011; 15: 260-4

75. Beran RG, Berkovic S, Buchanan N, et al. A double-blind, placebo-controlled crossover study of vigabatrin $2 \mathrm{~g} /$ day and 3 g/day in uncontrolled partial seizures. Seizure 1996; 5: 259-65

76. Sachdeo R, Narang-Sachdeo SK, Shumaker RC, et al. Tolerability and pharmacokinetics of monotherapy felbamate doses of 1,200-6,000 mg/day in subjects with epilepsy. Epilepsia 1997; 38: 887-92

77. Paul E, Conont KD, Dunne IE, et al. Urolithiasis on the ketogenic diet with concurrent topiramate or zonisamide therapy. Epilepsy Res 2010; 90: 151-6
78. Albsoul-Younes AM, Lasem Ha, Ajlouni SF, et al. Topiramate slow titration: improved efficacy and tolerability. Pediatr Neurol 2004; 31: 349-52

79. Wong IC, Mawer GE, Sander JW. Factors influencing the incidence of lamotrigine-related skin rash. Ann Pharmacother 1999; 33: 1037-42

80. Zaccara G, Franciotta D, Perucca E. Idiosyncratic adverse reactions to antiepileptic drugs. Epilepsia 2007; 48: 1223-44

81. Ju C, Uetrecht JP. Mechanism of idiosyncratic drug reactions: reactive metabolites formation, protein binding and the regulation of the immune system. Curr Drug Metab 2002; 3: 367-77

82. Sadeque AJM, Fisher MB, Korzekwa KR, et al. Human CYP2C9 mediate formation of the hepatotoxin 4-enevalproic acid. J Pharmacol Exp Ther 1997; 283: 698-703

83. Johnson TN. The development of drug metabolising enzymes and their influence on the susceptibility to adverse drug reactions in children. Toxicology 2003; 192: 37-48

84. Walgren JL, Mitchell MD, Thomson DC. Role of metabolism in drug-induced idiosyncratic hepatotoxicity. Crit Rev Toxicol 2005; 35: 325-61

85. Park BK, Pirmohamed M, Kitteringham NR. The role of drug disposition in drug hypersensitivity: a chemical, molecular and clinical perspective. Chem Res Toxicol 1998; 11: 969-88

86. Park BK, Coleman JW, Kitteringham NR. Drug disposition and drug hypersensitivity. Biochem Pharmacol 1987; 36: $581-90$

87. Uetrecht J. New concepts in immunology relevant to idiosyncratic drug reactions: the "danger hypothesis" and innate immune system. Chem Res Toxicol 1999; 12: 387-95

88. Matzinger P. The danger model: a renewed sense of self. Science 2002; 296: 301-5

89. Guengerich FP. Cytochrome P450 and other enzymes in drug metabolism and toxicity. AAPS J 2006; 8 (1): E101-11

90. Anderson GD. Children versus adults: pharmacokinetic and adverse-effect differences. Epilepsia 2002; 43 Suppl. 3: 53-9

91. Thompson CD, Kinter MT, Macdonald TL. Synthesis and in vitro reactivity of 3-carbamoyl-2- phenylpropionaldehyde and 2-phenylpropenal: putative reactive metabolites of felbamate. Chem Res Toxicol 1996; 9: 1225-9

92. Thompson CD, Gulden PH, Macdonald TL. Identification of modified atropaldehyde mercapturic acids in rat and human urine after felbamate administration. Chem Res Toxicol 1997; 10: 457-62

93. Kapetanovic IM, Torchin CD, Strong JM, et al. Reactivity of atropaldehyde, a felbamate metabolite in human liver tissue in vitro. Chem Biol Interact 2002; 142: 119-34

94. Dieckhaus CM, Roller SG, Santos WL, et al. Role of glutathione S-transferases A1-1, M1-1, and P1-1 in the detoxification of 2-phenylpropenal, a reactive felbamate metabolite. Chem Res Toxicol 2001; 14: 511-6

95. Popovic M, Nierkens S, Pieters R, et al. Investigating the role of 2-phenylpropenal in felbamate-induced idiosyncratic drug reactions. Chem Res Toxicol 2004; 17: 1568-76

96. Pellock JM, Faught E, Leppik IE, et al. Felbamate: consensus of current clinical experience. Epilepsy Res 2006; 71: 89-101

97. Zaccara G, Cincotta M, Borgheresi A, et al. Adverse motor effects induced by antiepileptic drugs. Epileptic Disord 2004; 6: 153-68 
98. Masmoudi K, Gras-Champel V, Masson H, et al. Parkinsonism and/or cognitive impairment with valproic acid therapy: a report of ten cases. Pharmacopsychiatry 2006; 39: $9-12$

99. Guerrini R, Belmonte A, Canapicchi R, et al. Reversible pseudoatrophy of the brain and mental deterioration associated with valproate treatment. Epilepsia 1998; 39: 27-32

100. Edwards SG, Hubbard V, Aylett S, et al. Concordance of primary generalised epilepsy and carbamazepine hypersensitivity in monozygotic twins. Postgrad Med 1999; 75: 680-1

101. Shear NH, Spielberg SP. Anticonvulsant hypersensitivity syndrome: in vitro risk assessment. J Clin Invest 1988; 82: 1826-32

102. Ferrell Jr PB, McLeod HL. Carbamazepine, HLA-B*1502 and risk of Stevens-Johnson syndrome and toxic epidermal necrolysis: US FDA recommendations. Pharmacogenomics 2008; 9 (10): 1543-6

103. Chung WH, Hung SI, Hong HS, et al. Medical genetics: a marker for Stevens-Johnson syndrome. Nature 2004; 428: 486

104. Dreifuss FE, Langer DH. Hepatic considerations in the use of antiepileptic drugs. Epilepsia 1987; 28: S23-9

105. Perucca E. Clinical pharmacokinetics of new generation antiepileptic drugs at the extremes of age. Clin Pharmacokinet 2006; 45: 351-63

106. Stewart JD, Horvath R, Baruffini E, et al. Polymerase $\gamma$ gene POLG determines the risk of sodium valproateinduced liver toxicity. Hepatology 2010; 52: 1791-6

107. Dreifuss FE, Langer DH, Moline KA, et al. Valproic acid hepatic fatalities: II. US experience since 1984. Neurology 1989; 139: 201-7

108. Hirsch LJ, Arif H, Nahm EA, et al. Cross-sensitivity of skin rashes with antiepileptic drug use. Neurology 2008; 71: 1527-34

109. Peyrière H, Dereure O, Breton H, et al. Variability in the clinical pattern of cutaneous side effects of drugs with systemic symptoms: does a DRESS syndrome really exist? Br J Dermatol 2006; 155: 422-8

110. Rzany B, Correia O, Kelly JP, et al. Risk of StevensJohnson syndrome and toxic epidermal necrolysis during first weeks of antiepileptic therapy: a case-control study. Study Group of the International Case Control Study on Severe Cutaneous Adverse Reactions. Lancet 1999; 353: 2190-4

111. Revuz J, Penso D, Roujeau JC, et al. Toxic epidermal necrolysis: clinical findings and prognosis factors in 87 patients. Arch Dermatol 1987; 123: 1160-5

112. Binaghi M, Koso M, Saiag P, et al. Ocular involvement in Lyell's syndrome: incidence, evolution, prognosis. Ophtalmologie 1988; 2: 121-2

113. Schopf E, Stuhmer A, Rzany B, et al. Toxic epidermal necrolysis and Stevens-Johnson syndrome: an epidemiologic study from West Germany. Arch Dermatol 1991; 127: 839-42

114. Roujeau JC, Stern RS. Severe adverse cutaneous reactions to drugs. N Engl J Med 1994; 331: 1272-85

115. Bastuji-Garin S, Rzany B, Stern RS, et al. Clinical classification of cases of toxic epidermal necrolysis, StevensJohnson syndrome, and erythema multiforme. Arch Dermatol 1993; 129: 92-6
116. Kaufman DW, Kelly JP, Anderson T, et al. Evaluation of case reports of aplastic anemia among patients treated with felbamate. Epilepsia 1997; 38: 1265-9

117. Blackbum SC, Oliart D, Garcia RL, et al. Antiepileptic and blood dyscrasia; a cohort study. Pharmacotherapy 1998; 18: $1277-83$

118. Kaplowitz N. Drug-induced liver injury. Clin Infect Dis 2004; 38 Suppl. 2: S44-8

119. Binek J, Hany A, Heer M. Valproic acid-induced pancreatitis: report of a case and review of literature. J Clin Gastroenterol 1991; 13: 690-3

120. Zaccara G, Campostrini R, Paganini M, et al. Acute changes of blood ammonia may predict short-term effects of valproic acid. Neurology 1984; 34: 1519-21

121. Harrison MB, Lyons GR, Landow ER. Phenytoin and dyskinesias: a report of two cases and review of the literature. Mov Disord 1993; 8: 19-27

122. Fraunfelder FW, Fraunfelder FT, Keates EU. Topiramate, associated, acute, secondary angle-closure glaucoma. Ophthalmology 2004; 111: 109-11

123. Watanabe T, Yoshikawa H, Yamazaki S, et al. Secondary renal Fanconi syndrome caused by valproate therapy. Pediatr Nephrol 2005; 20: 814-7

124. Guerrini R. Epilepsy in children. Lancet 2006; 367: 499-524

125. Sulzbacher S, Farwell JR, Temkin N, et al. Late cognitive effects of early treatment with phenobarbital. Clin Pediatr 1999; 38: 387-94

126. Donati F, Gobbi G, Campistol J, et al. The cognitive effects of oxcarbazepine versus carbamazepine or valproate in newly diagnosed children with partial seizures. Seizure 2007; 16: 670-9

127. Kang HC, Eun BL, Wu LC, et al. The effects on cognitive function and behavioural problems of topiramate compared to carbamazepine as monotherapy for children with benign rolandic epilepsy. Epilepsia 2007; 48: 1716-23

128. Bootsma HP, Aldenkamp AP, Diepman L, et al. The effect of antiepileptic drugs on cognition: patient perceived cognitive problems of topiramate versus levetiracetam in clinical practice. Epilepsia 2006; 47 Suppl. 2: 24-7

129. Kossoff EH, Bergey GK, Freeman JM, et al. Levetiracetam psychosis in children with epilepsy. Epilepsia 2001; 42: 1611-3

130. Best JL, Acheson JF. The natural history of vigabatrin associated visual field defects in patients electing to continue their medication. Eye 2005; 19: 41-4

131. Kraemer G, Ried S, Landau K, et al. Vigabatrin: reversibility of severe concentric visual field defects after early detection and drug withdrawal. A case report. Epilepsia 2000; 41 Suppl.: 144

132. Guideline for prescribing vigabatrin in children has been revised. Vigabatrin Paediatric Advisory Group. BMJ 2000; 320 (7246): 1404-5

133. Nousiainen I, Mantyjarvi M, Kälviäinen R. No reversion in vigabatrin-associated field defects. Neurology 2001; 57: 1916-7

Correspondence: Professor Renzo Guerrini, MD, Children's Hospital A. Meyer, University of Florence, Viale Pieraccini 24, 50139 Florence, Italy.

E-mail: r.guerrini@meyer.it 